\title{
Paradoxes in supply chains: a conceptual framework for packed products
}

\author{
Henrik Pålsson \\ Faculty of Engineering, Lund University, Lund, Sweden, and \\ Erik Sandberg \\ Department of Logistics and Quality Management, Linköping University, \\ Linköping, Sweden
}

\begin{abstract}
Purpose - Grounded in paradox theory, and with the objective of structuring and extending existing knowledge of conflicts of interest (e.g. trade-offs) in packaging logistics, the purpose of this paper is to identify categories of paradoxical tensions in packaging systems used in supply chains, and to develop a conceptual framework that describes these categories.

Design/methodology/approach - This research uses a theory building approach. It develops a conceptual framework of paradoxical tensions for packed products in supply chains. It revises and extends current knowledge in this domain by applying paradox theory from organisational research.

Findings - The paper develops a generic, conceptual framework that identifies, categorises and describes packed product paradoxes on two system levels: supply chain and company levels. The categories of paradoxes refer to performing, organising, belonging and learning.

Research limitations/implications - The framework provides a new theoretical explanation of conflicts of interest in packaging logistics in terms of paradoxical tensions related to packed products in supply chains. It structures and increases general understanding of such tensions within and between actors in a supply chain. The paper also discusses differences in terminology between tensions which are possible to settle and those which lead to paradoxes.

Practical implications - The framework provides a structure for analysing the organisational impact of strategic packaging decisions. It can help highlight different stakeholders' organisational constraints related to packaging.

Originality/value - The framework's systematic categorisation of four types of paradoxical tensions, with thorough descriptions of the meaning of packed product paradoxes of each type, offers an expanded and indepth explanation of the organisational impacts of packed products in supply chains.
\end{abstract}

Keywords Packaging, Paradoxes, Tensions, Trade-offs

Paper type Conceptual paper

\section{Introduction}

To be effectively managed in supply chains, products are protected by packaging. Packaging must fulfil several functions to meet the economic, environmental, ergonomic and legal requirements placed upon it. Packaging should protect and contain products, unitise and apportion products, provide convenience and communication, and enable logistics efficiency. Logistics efficiency originates from the fact that packaging influences every single logistics activity throughout the supply chain from point of filling to point of emptying, as well as

(C) Henrik Pålsson and Erik Sandberg. Published by Emerald Publishing Limited. This article is published under the Creative Commons Attribution (CC BY 4.0) licence. Anyone may reproduce, distribute, translate and create derivative works of this article (for both commercial and non-commercial purposes), subject to full attribution to the original publication and authors. The full terms of this licence may be seen at http://creativecommons.org/licences/by/4.0/legalcode.

The authors would like to thank Formas (the Swedish government research council for sustainable development) for funding this research (registration number: 2017-00792).

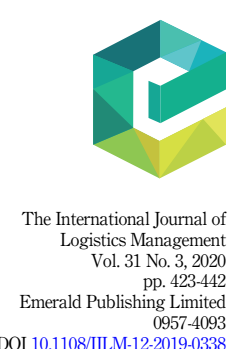

DOI 10.1108/IJLM-12-2019-0338 
IJLM 31,3

several activities within reverse logistics and packaging end-of-life, such as returns, recycling and reuse. Usual logistics activities that are influenced by packaging occur, for instance, at a supplier's or producer's (e.g. filling, storing and handling), during transport to warehouses (e.g. volume and weight efficiency), within warehouses (e.g. picking, stacking and storing), during distribution to stores (e.g. loading and unloading, and volume utilisation), within stores (e.g. replenishment, handling and waste handling), at consumers' (e.g. handling and emptying), and finally, in the recycling process. This "interface between packaging and logistics throughout supply chains, which demonstrates and supports the importance of viewing the physical flow of goods and its related information flow as one integrated system" (p. 5, Pålsson, 2018) is defined as "packaging logistics". In short, packaging logistics operationalizes supply chain management (SCM) philosophy. It contributes to the operational understanding of SCM concepts and theories, such as supply chain integration, collaboration and organisation.

Packaging has become a crucial and increasingly complex matter, driven by increased legislation and consumer awareness of the environmental performance of packaging (White et al., 2015), globalisation (Trent and Monczka, 2003) and the need for short lead times (Christopher, 2016). Managing these complexities can lead to significant positive impacts on the economic and environmental performance of supply chain actors (Çankaya, and Sezen, 2019). The complexity arises from the fact that no single package can fulfil all the requirements for packed products. It takes a packaging system in which primary (in contact with the product), secondary (contains a number of primary packages) and tertiary packaging (contains a number of secondary packages) interact with each other. For instance, if the secondary packaging provides sufficient product protection, the need for primary packaging protection can be reduced. In addition to the complexities within the packaging system itself, complexities also arise between companies and organisational areas since several of them have interests in the packaging system. These include marketing for increased sales and logistics for increased material handling and transport efficiency, and various requirements from companies in the supply chain.

The view taken in this paper is that these complexities are caused by conflicts of interest in packaging both within and between organisations. The need to identify and make informed decisions regarding these conflicts, mainly referred to as trade-offs in logistics research, has previously been well described and motivated in the literature (e.g. Lockamy III, 1995; Paine, 1990; Pålsson, 2018). The current literature analyses trade-offs in packaging systems through the use of different models and methods, such as a packaging scorecard (Olsmats and Dominic, 2003), packaging selection models in specific industries (e.g. Lai et al., 2008; Pålsson et al., 2013), and life-cycle assessment (LCA) tools (Grönman et al., 2013; Verghese et al., 2010). The literature also suggests empirically based tools to identify trade-offs between costs and marketing (e.g. García-Arca and Prado Prado, 2008) and the use of contracts (Selviaridis et al., 2016). Packaging logistics knowledge also emphasises the need for organisational support to manage packaging trade-offs within and between organisations. For instance, based on a case study, Klevås (2005) suggests that to secure high logistics performance, the organisation of packaging in a product-developing company should have strong links to both logistics and product development. In a similar vein, Bramklev (2009) focuses on the organisational links between product and packaging development. To minimise the environmental footprint of packaging in supply chains, Molina-Besch and Pålsson (2014) show that internal and external collaborations are necessary.

The current discussions and analyses of conflicts of interest in packaging logistics originate from a systems approach (Hellström and Olsson, 2017), even though this is not always explicitly stated. Such an approach acknowledges the existence of trade-offs (Azzi et al., 2012). It also accentuates how a change in one part of the system can cause disproportionate changes in the whole system due to interactions with other factors 
(Mollenkopf et al., 2005). However, the approach has been less effective in describing and systematically categorising the organisational impacts of trade-offs despite the fact that the multiple purposes of, and stakeholder interests in, packaging create organisational tensions, such as contradictory performance goals on packaging (García-Arca and Prado Prado, 2008).

Packaging logistics research on conflicts of interest is limited in the sense that, despite different origins and characteristics, they are generally only referred to as trade-offs. For instance, there might be trade-offs between cost and value, between packaging requirements regarding sales attributes and enabling logistics efficiency, or between different stakeholders' objectives of packaging (Hellström and Olsson, 2017, p. 42). The most common trade-offs in packaging logistics literature refer to those about packaging performance. For instance, de Koijer et al. (2017a) highlight trade-offs between functional requirements on packaging and commercial targets, whereas Pålsson and Hellström (2016) discuss trade-offs on a broader system level - between packaging requirements from different supply chain actors. Another type of trade-offs depends on organisational structure, both within and between companies in the supply chain (de Koijer et al., 2017b). These tradeoffs require an integrated view of product and packaging development for example, and cooperation between departments and companies (Svanes et al., 2010). A third type of trade-offs depends on varying attitudes and assessment criteria for packaging by different departments, organisations and consumers. The attitudes towards changing packaging often vary, which leads to trade-offs (de Koijer et al., 2017a). For instance, Steenis et al. (2017) studied sustainable packaging, and emphasise that "different materials communicate different levels of sustainability to consumers, which may not be in line with LCA outcomes. Therefore, even though consumers generally hold positive attitudes toward sustainable packaging, it should not at all be assumed that consumers will readily make the right environmental choice" (p. 295). A final type of trade-offs refers to development of packaging knowledge. A study found that sustainable packaging practices focus on incremental innovation and training (de Koijer et al., 2017a). Consequently, radical innovation and knowledge development for sustainable packaging is addressed to a lesser degree.

Another limitation of not clearly distinguishing between different types of trade-offs is that the type affects the possibility to find a solution. For instance, a trade-off between having a large package for maximal visibility in a store is not compatible with a logistics requirement of having a small package - a compromise is necessary. However, a trade-off between economic and environmental requirements may be fulfilled with an innovative packaging solution, which fulfils both requirements (Franey et al., 2010). Consequently, the scientific knowledge of trade-offs in packaging logistics would increase if the trade-offs could be more fine-tuned, for instance, by being categorised according to type and characteristics.

As a means to doing so, this paper applies paradox theory, a new theoretical lens that stems from the field of organisational research. The application of organisation theory "has the potential to offer provocative and helpful wisdom to the field of supply chain management, yet organisation theory's potential has remained largely underdeveloped in the supply chain arena" (Ketchen and Hult, 2007, p. 455). Paradoxes are typically defined as "contradictory yet interrelated elements that exist simultaneously and persist over time" (Smith and Lewis, 2011, p. 382). In packaging logistics, paradox theory can provide researchers with new tools for analysis and in-depth understanding of organisational tensions related to the packaging system. In essence, the paradox theory supports researchers on how to consider these tensions, establish whether there are different types of tensions, and how to manage them (van der Byl and Slawinski, 2015).

Grounded in paradox theory, and with the objective of structuring and extending existing knowledge of conflicts of interest (e.g. trade-offs) in packaging logistics, the purpose of this paper is to identify categories of paradoxical tensions in packaging systems used in supply chains, and to develop a conceptual framework that describes these categories. The paper
Paradoxes in supply chains 
IJLM

31,3

426

discusses the distinction between paradoxical tensions and other types of tensions, which can be settled. It focuses on paradoxical tensions in the packaging systems throughout their entire lifecycle, and covers intra- and interorganisational paradoxes that derive from packaging. Products are not the primary focus, but they are considered when they come into contact with packaging, that is, from the point of filling to the point of emptying the package. To highlight the inclusion of products in the packaging system, the paper also uses the synonym packed products for the packaging system.

Despite long-term recognition in both theory and practice, "comparatively little work has been undertaken to understand the way that packaging solutions are developed within supply chains and the impact that those solutions have upon the remainder of the supply chain" (White et al., 2015, pp. 6553-6554). Ultimately, the conceptual framework developed with a novel perspective in this paper revises current knowledge of trade-offs in packaging logistics. The framework establishes a new conceptual base for analytical thinking around packed product paradoxes upon which future empirical studies can be based. Such studied should add more specific knowledge of contradictory interests in the packed product supply chain.

The remainder of the paper presents the methodology and a review of paradox theory. It then develops a new conceptual framework of packed product paradoxes. This is followed by a discussion section and a section, on conclusions and future research.

\section{Methodology}

This conceptual paper represents a first phase of current research activities to describe and categorise paradoxical tensions inherent in a packaging logistics context. It is based on a theory building approach (Meredith, 1993) that involves the establishment and development of definitions, domains, relationships and predictions (Wacker, 1998). Such an approach is crucial for emerging and/or growing research areas (Kovacs and Spens, 2007) such as packaging logistics.

The paper develops a conceptual framework that contributes to new domain-based knowledge (MacInnis, 2011) in the area of packaging logistics. It contributes with a revision of current knowledge in this domain, as it takes "a novel perspective on something that has already been identified” (MacInnis, 2011, p. 143), by applying paradox theory from organisational research. Logistics and SCM scholars have a long tradition of such a "borrowing" strategy and the advantages gained are well established (Defee et al., 2010; Halldorsson et al., 2015). Paradox theory is new in the realm of logistics and SCM research, with the potential to break new ground (Maalouf and Gammelgaard, 2016; Sandberg, 2017). In addition to scientific utility (Corley and Gioia, 2011) that supports the analysis of existing tensions among scholars, such a framework can serve as an analysis tool for increased understanding among practitioners, i.e. constitute a contribution towards practical utility (Corley and Gioia, 2011; Wacker, 1998).

The conceptual framework emanates from the need to understand packaging logistics trade-offs better. Paradox theory helps to revise packaging logistics knowledge with an alternative, not previously applied, frame of reference in this setting (MacInnis, 2011). When applying paradox theory, we take a stance in Smith and Lewis' (2011) seminal categorisation of performing, organising, belonging and learning paradoxes; this is based on earlier work by Lewis (2000) and Luscher and Lewis (2008), and later applied by Schad et al. (2016), Sandberg (2017) and Hahn et al. (2018). We take this stance as it consolidates much of the previous literature on paradoxes, and it offers a useful structure to develop the general understanding of trade-offs in packaging logistics. In this paper, the categorisation serves as a useful platform to which other relevant paradox research articles are related. In addition to the categorisation by Smith and Lewis (2011), and since packaging influences all logistics 
activities from the point of filling to the point of emptying, we as researchers identified possible occurrences of paradoxes at two system levels: the company (intra-organisational) level, and the supply chain level. The proposed framework thus includes intra- as well as inter-organisational perspectives related to packaging. The combination of Smith and Lewis' four categories and the two system levels resulted in a draft framework with a total of eight distinct categories of paradoxical tensions.

To refine the framework, we reviewed existing packaging logistics literature focused on content related to conflicting goals and objectives, tensions, paradoxes and trade-offs, using Smith and Lewis' (2011) terminology of "paradoxes" and "tensions" as an overall structure. This review aimed to provide details within each of the categories. As such, the literature review provided a rich description of the phenomenon studied, which helped to ensure the external validity of the framework (Meredith, 1993).

The first draft of the conceptual framework was iteratively refined, as described by Meredith (1993), through individual reviews by the authors. The reviews focused on the framework's consistency and logic, its application of paradox theory, and its categorisation of different types of paradoxical tensions in packaging logistics. The authors discussed the individual reviews in-depth, which resulted in modifications of the conceptual framework. The authors then carried out further individual reviews until neither of the authors questioned any of the content in the framework. The final step was to validate the conceptual framework with fellow researchers in the field. We presented, discussed and gained feedback in an international academic conference on logistics and supply chain management, where approximately twenty peers participated in our seminar, and in an internal workshop with ten research colleagues.

\section{Paradox theory}

The growing body of literature on organisational tensions, in the form of paradox theory, takes its stance in the existence of contradictory goals and objectives that need to be managed by an organisation. It recognises that there may be contradictory yet interrelated elements in an organisation that seem logical in isolation, but absurd and irrational when posed against each other (Smith and Lewis, 2011; Lewis, 2000; Poole and van de Ven, 1989; Schad et al., 2016; Waldman et al., 2019). These elements create competing designs within an organisation that continuously challenge its existing rationale (Jarzabkowski et al., 2013). In contrast to earlier approaches, such as the contingency theory, paradox theory suggests that high, sustainable performance originates not from selecting one element, but from the ability to accept, embrace and confront the elements simultaneously, thus going beyond an "either/or" choice to a "both/and" view of how to manage contradictions (Lewis and Smith, 2014; Waldman et al., 2019). As a result, organisational tensions must be continually acknowledged and managed over time (Nosella et al., 2012; Poole and van de Ven, 1989; Schad et al., 2016). Either defensively or proactively handled (Hahn et al., 2018; Schad et al., 2016), organisational awareness of these tensions and their impact on company performance is vital (Schad et al., 2016). If not managed properly, the contradictory forces inherent in the paradox may neutralise each other's beneficial sides (Gebert et al., 2010). On the other hand, awareness of paradoxes may constitute a driving force for the innovation and development of organisations (Graetz and Smith, 2009; Gebert et al., 2010; Hargrave and van de Ven, 2017; Schad et al., 2016; Waldman et al., 2019). Organisational change naturally puts pressure on the objectives and goals behind the organisational efforts, which means that paradoxes become more apparent (Maalouf and Gammelgaard, 2016; Jarzakowski et al., 2013).

In SCM and logistics research, contradictions are traditionally acknowledged as tradeoffs. In recent years, paradox theory has slowly gained momentum, as a means of further understanding these contradictions (Matthews et al., 2016; Sandberg, 2017; Xiao et al., 2019). The literature recognises that in the light of sustainability, paradox theory offers improved 
IJLM 31,3 insights into how the different dimensions of economic, environmental and social sustainability can be managed and understood simultaneously (Hahn et al., 2018; van der Byl and Slawinski, 2015). For instance, Xiao et al. (2019) demonstrated the value of "paradoxical sensemaking" for sustainability among purchasing managers. Hahn et al. (2015) suggested an integrative framework of sustainability paradoxes, and elaborated on approaches for how to manage these. Brix-Asala et al. (2018) explored sustainability paradoxes in the electronics industry from a company perspective. They emphasised tensions caused by different levels of sustainability efforts among supply chain members. Overall, in line with the suggestion by Ketchen and Hult (2007), paradox theory offers a suitable lens through which to view organisational complexity, such as a supply chain, which includes multiple goals, interests and actors.

The nomenclature regarding paradoxes and their relation to trade-offs needs clarification. Making a trade-off means choosing a path where another path is neglected, at least partially (Wannags and Gold, 2020). It can be seen as a "win-lose" situation. The term "trade-off" in logistics literature is close to "tension" in organisational research. "Trade-offs" and "tensions" are generic terms often applied without further definitions, but recent organisational research on paradox theory has explored and elaborated different kinds of tensions (Smith and Lewis, 2011; Schad et al., 2016; van der Byl and Slawinski, 2015). Paradox theory divides tensions into those that can be settled and those that cannot; the latter are labelled "paradoxes". Paradoxical tensions persist over time and their core elements remain impervious to resolution, even in highly dynamic environments (Schad et al., 2016). Lewis and Smith (2014) divided "non-paradoxical" tensions (that are possible to settle) into dilemmas and dialectics. Dilemmas involve an "either/or" choice where one side must be selected at the cost of the other, whereas dialectics refer to tensions that can be avoided by finding a solution that integrates the opposing arguments causing conflict. Instead of referring only to trade-offs, paradox theory thus enables a more distinct understanding of packaging logistics challenges, in which conflicting interests can be systematically juxtaposed and explored. The conceptual framework developed in section 4 helps in identifying paradoxical tensions. To judge whether a tension can be settled or not may be challenging, as it can be perceived differently by different observers (Gaim and Wåhlin, 2016). To help researchers and practitioners to distinguish between different types of tensions and highlight the implications of the proposed framework the discussion section in this paper elaborates on different types of tensions. The paper does not distinguish between dilemmas and dialectics, as this is too detailed for the scope of this paper. To identify, analyse and understand paradoxes, Smith and Lewis (2011, p. 383) categorise four types of organisational paradoxes:

(1) Performing paradoxes address tensions that originate from complexity in differentiated organisational units. This results in multiple and competing goals and objectives for different stakeholders within and between organisations (Jarzabkowski et al., 2013). A well-known performing paradox relates to corporate sustainability, which is represented by the three different, yet interdependent dimensions of economic, environmental and social objectives (Hahn et al., 2018). This sustainability paradox is also acknowledged in packaging logistics, for instance, between economic and environmental performance. Other packaging-related performing paradoxes concern the use of minimal amounts of packaging material and avoiding product waste (Grönman et al., 2013) for example.

(2) Organising paradoxes occur when there are competing organisational designs and processes to achieve a desired outcome (Lewis, 2000; Schad et al., 2016). Organisations and supply chains typically comprise a variety of subunits that act both independently and interdependently (Jarzabkowski et al., 2013). This may lead to 
paradoxes because of conflicts between commitment, trust and creativity on the one hand, and efficiency, discipline and order on the other. Typical paradoxes are collaboration vs competition, empowerment vs direction, and alignment vs flexibility (Schad et al., 2016). In a similar vein, Vangen (2012) highlights the paradoxical nature of collaboration and suggests that collaboration embraces a variety of tensions related to organising, e.g. cooperation vs competition, design vs emergence, and trust vs vigilance. Overall, collaboration causes a number of organising paradoxes related to its management and governance (Vangen, 2012). In packaging logistics, such collaboration-related organising paradoxes may include the extent to which a producer should integrate suppliers and customers in packaging development and selection processes.

(3) Belonging paradoxes originate from tensions regarding values, roles and memberships within and between different organisations (e.g. a supply chain). They also include the tensions between collective and individual affiliations (Schad et al., 2016; Waldman et al., 2019). For instance, supply chain managers can represent the company, the supply chain or themselves as individuals. This means that belonging paradoxes "foster tensions between the individual and the collective and between competing values, roles, and memberships" (Smith and Lewis, 2011, p. 383). This is often challenging in supply chains where companies, but also individuals in the different companies, have different values and beliefs that need to be balanced. An instance where this becomes clear is that of values related to sustainability issues (Xiao et al., 2019).

(4) Learning paradoxes arise when new knowledge is developed to adjust, renew or change a supply chain. These paradoxes foster tensions between replacing past understandings with new, future-proof practices (Maalouf and Gammelgaard, 2016). As old experiences and know-how are challenged, the development of new knowledge may conflict with current understanding in an organisation. This may involve the challenging act of balance between exploration and exploitation (March, 1991), and short- vs. long-term company objectives related to learning (Slawinski and Bansal, 2012, 2015). In a packaging environment, knowledge about minimising the environmental impacts of packaging has led to public authorities and companies focusing on packaging material minimisation (Vergese and Lewis, 2007). However, recent knowledge, based on a systems approach, shows that product waste, and the volume and weight efficiency of packaging may have even greater environmental impacts than packaging material (Pålsson, 2018). This is a typical learning paradox for these organisations to develop their knowledge in the area of packaging logistics, which may generate tensions both within each organisation and in the supply chain.

\section{Packed product paradoxes (PPP) conceptual framework}

A conceptual framework of paradoxical tensions was developed by analysing packaging logistics through the paradox lens, with an emphasis on the categorisation of paradoxes by Smith and Lewis (2011). A review of conflicting goals and objectives, tensions, paradoxes and trade-offs in packaging logistics literature helped to illustrate the paradoxical tensions. The framework describes these at two system levels. Figure 1 illustrates the occurrence and structure of the two system levels of paradoxical tensions that are considered in the PPP conceptual framework. System level 1 relates to the supply chain, and system level 2 relates to the companies handling the packed product in the supply chain. The first system level has paradoxical tensions between supply chain organisations (supply chain paradoxes). As packages usually follow the product throughout the supply chain, they are essential for the 
IJLM
31,3

430

performance of not only producers, but also for logistics services providers, distributors, retailers, etc. The packaging requirements of each organisation are not always compatible. The second system level refers to each company in the supply chain. Here, packaging-related paradoxes arise between organisational units within a company, mainly caused by conflicts that occur during development and selection of packaging systems (intra-organisational paradoxes). For instance, an environmental packaging requirement from one organisational unit in the company may be in conflict with a marketing requirement in another organisational unit in the company.

By applying paradox theory to packed products in supply chains, paradoxical tensions on the two system levels (Figure 1) can be understood in an integrated framework. The integrated framework is beneficial because the packaging system being considered is essentially the same (although it can be slightly modified, for example, after repacking activities in a warehouse) on both system levels. Table 1 presents the PPP conceptual framework. It describes the types of paradoxical tensions to consider at both system levels in each paradox category. As a result, the PPP framework helps to identify and structure paradoxical tensions, which in a second analysis step should be categorised as unsolvable (i.e. paradoxes) or solvable tensions (e.g. trade-offs, dilemmas or dialectics).

In the next sections, paradoxical tensions in packaging logistics are further elaborated based on these two system levels, and on Smith and Lewis' (2011) four paradox categories.

\subsection{Performing paradoxes}

Performing paradoxes refer to tensions between performance goals. These occur naturally in organisations, and in supply chains, when stakeholders have different interests and goals. In packaging logistics, as in logistics and SCM in general, performing paradoxes have been acknowledged for a long time (Kassaye and Verma, 1992; Livingstone and Sparks, 1994). They were discussed as early as the 1990s (Livingstone and Sparks, 1994), but they have received increased attention in recent years (Freichel et al., 2020; White et al., 2015).

In general, performing paradoxes may occur between goals for an individual packaging level on the one hand, and goals for the entire packaging system on the other (Pålsson and Hellström, 2016). For instance, a more expensive primary packaging may allow for cheaper secondary packaging, which may lead to a cheaper overall packaging system.

On system level 1, the supply chain level, companies in the supply chain can have contradictory performance goals for the packaging system (Hellström and Saghir, 2007; Pålsson and Hellström, 2016). Different supply chain organisations may have different focus points on the importance of different packaging features, the time horizon on which packaging performance is evaluated (Lockamy III, 1995), and the system boundaries that are taken into account when packaging performance is assessed (Bramklev, 2009). For instance,

Figure 1.

Packed product paradoxes (PPP) on two system levels

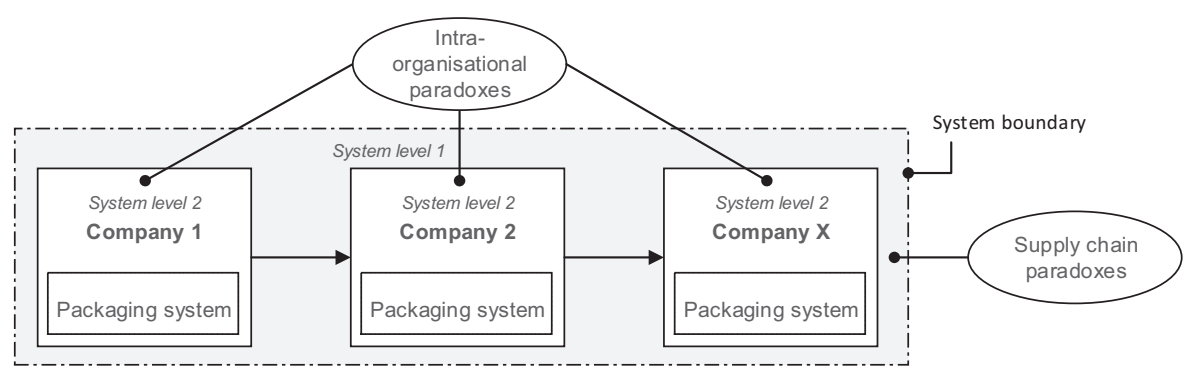




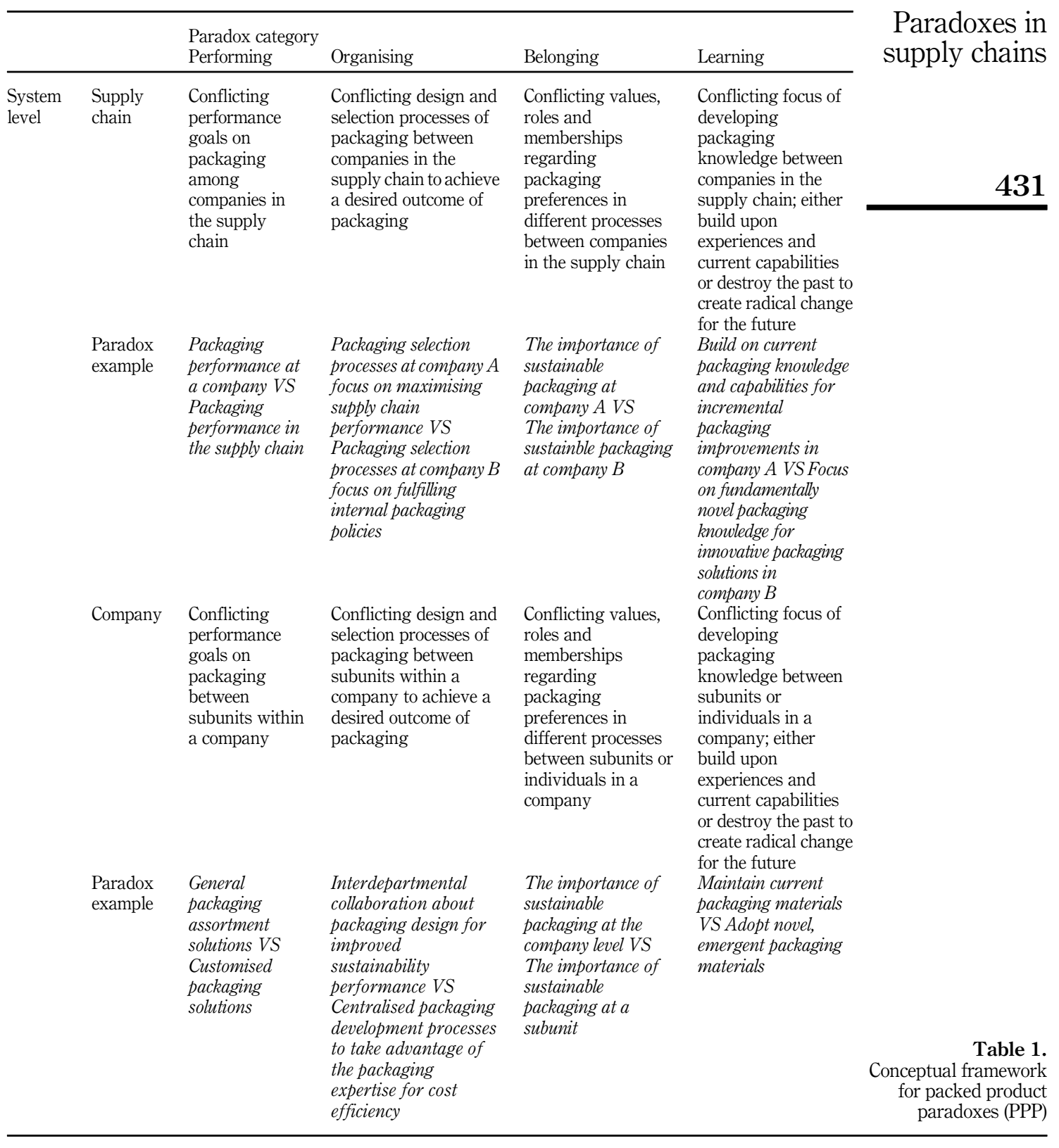

paradoxes may arise between different organisations' foci on packaging features related to logistics, marketing, environmental impact, ergonomics and production (Pålsson, 2018). An exploratory study of shippers' possibilities to increase the load factor in road transport indicates a paradoxical tension between packaging system efficiency and two other 
IJLM

31,3

indicators (loading efficiency and booking efficiency) (Santén, 2017). These three indicators are interrelated, but with slightly contradictory goals. Another example is that paradoxes may arise between organisations' foci on primarily evaluating the long-term packaging performance and others the short-term (Twede and Clarke, 2005). An organisation may want to invest in a reusable packaging system with a pay-off time of several years, while another prefers the one-way packaging system with lower fixed costs (Twede and Clarke, 2005). To maximise cost and environmental efficiency, the organisations may need to combine reusable and one-way packaging (Bortolini et al., 2018).

On system level 2, within a company, performing paradoxes may appear between contradictory packaging development goals and between subunits (intra-organisational). This is a result of different aspiration regarding the outcome of packaging design. The subunits in a company (marketing, production, etc.) often have contradictory performance goals for the packaging system (Lockamy III, 1995; Pålsson et al., 2013), as they focus on contradictory packaging features and aim for contradictory designs of the same packaging feature (Kassaye and Verma, 1992). For instance, a goal to obtain cost efficiency may lead to general packaging solutions, whereas a goal to maximise service and responsiveness may lead to customised packaging solutions (White et al., 2015). An example of potential paradoxes between subunits is that transport and logistics subunits may opt for cost-efficient transport and handling, whereas a sales subunit may focus on the ability of packaging to attract customers (Pålsson and Hellström, 2016).

\subsection{Organising paradoxes}

Organising paradoxes stem from conflicting processes in the organisational structure, typically between the variables of control vs flexibility, collaboration vs competition, and empowerment vs direction. In short, different organisational designs of packaging processes result in different organisational achievements (Smith and Lewis, 2011). Understanding the organising paradoxes related to packaging contributes to the understanding of mechanisms that facilitate or hinder the adoption of supply chain innovations (Damanpour, 1991).

On system level 1, organising paradoxes related to the design and selection processes of packaging exist, as supply chain members should collaborate for successful packaging design (García-Arca et al., 2017), which is adjusted to the supply chain. However, at the same time, they compete in terms of maximising the packaging design for each company (Pålsson and Hellström, 2016). The paradox stems from the fact that the optimal packaging design for an individual company is often suboptimal for the whole supply chain (Freichel et al., 2020; Pålsson, 2018). As exemplified for reusable packaging, these supply chains are usually quite complex with more than a single sender and a single recipient (Mahmoudi and Parviziomran, 2020). As a result, to maximise the outcome of packaging for both individual companies and the supply chain, the design and selection processes of packaging may include contradictory elements of collaboration and competition among the companies in the supply chain (Bramklev, 2009). An example is the development of a new packaging solution for a tea light (Klevås et al., 2006). Both the manufacturer and the retailer were positive to the new packaging solution, but initially, the manufacturer had a competitive approach in order for the retailer to bear the investment cost in a new packaging machine; this led to a collaborative approach for finalising the new packaging solution. Organising paradoxes also exist because each supply chain member may want to authorise their part of the packaging processes to align with their packaging policies, but at the same time, the processes should fulfil the overall supply chain requirements and direction (García-Arca and Prado Prado, 2008). In a study of omni-channel packaging, Freichel et al. (2020) found that collaboration between organisations in the supply chain is necessary to identify and integrate all packaging requirements as early as in the product development phase. Similar findings have been identified for other types of packaging (Pålsson, 2018). Nevertheless, the direction of a focal 
firm's packaging policies may create a mismatch with the packaging solutions of other organisations in the supply chain resulting in inefficiencies for the suppliers (Freichel et al., 2020). Furthermore, organising paradoxes may exist since packaging selection and development processes need clear structures (be controlled) to be efficient, but they also need to be flexible in terms of time, content and resources to incorporate new requirements and open up for innovative packaging solutions (Lockamy III, 1995). An example of an organising paradox is whether the packaging selection process primarily regards supply chain members as collaborative partners so that their supply chain requirements can be incorporated into the packaging solution or if the process uses a competitive approach with a focus on fulfilling and prioritising internal requirements on packaging to maximise the internal performance of packaging (García-Arca et al., 2019). Challenges faced with the collaborative approach are sharing costs and benefits between companies (Molina-Besch and Pålsson, 2016), and how to prioritise the different companies' requirements (García-Arca et al., 2017). The competitive approach suffers from the risk of suboptimisation (Hellström and Saghir, 2007).

On system level 2, companies may have contradictory requirements on organising packaging development and selection processes. Interdepartmental collaboration about packaging design can improve sustainability performance (García-Arca et al., 2017), but having a centralised packaging authority can take advantage of in-house packaging expertise and have control of the whole packaging assortment (Klevås, 2005), which can lower costs for packaging held in stock and for transport (Freichel et al., 2020). Thus, the organisation of packaging development should have high authority (empowerment), but also be guided (directed) by other business functions to customise packaging (Klevås, 2005). This includes whether the company focuses on collaboration within the packaging function to utilise the packaging expertise or on promoting fruitful competition between business functions to utilise contextual knowledge from marketing, production and other areas (White et al., 2015). In processes with high packaging authority in the company, the packaging selection may lead to advanced, unified and cost-efficient packaging assortment, but they may be less customised and thus incompatible with contextual requirements from other business functions, such as marketing and production (Klevås, 2005).

\subsection{Belonging paradoxes}

The belonging paradox category addresses paradoxes that stem from conflicting values, norms and roles in the organisation. They address conflicts of interest between hierarchical levels in organisations, ranging from individuals to company levels via a number of hierarchical subunits, and beyond single company boundaries, thus instigating tensions among supply chain members. The matter of loyalty to certain values and memberships becomes an issue, since different hierarchical levels may have competing goals and requirements. For instance, in a packaging logistics context, belonging paradoxes may arise between the packaging development organisation and the overall company organisation (Klevås, 2005).

On system level 1, companies may have competing values leading to different preferences about packaging that may result in paradoxical tensions between environmental and economic efficiencies, and between operational efficiency and customer value, or sales (Kassaye and Verma, 1992). As a result, companies in a supply chain may have different packaging material preferences, such as mainly using fibre-based materials, plastics or other materials perceived as sustainable (Steenis et al., 2017). On the supply chain level, each company has different roles. Organisations can either see themselves as belonging to the company or to the supply chain (Ketchen and Hult, 2007), which may result in belonging paradoxes between selecting packaging solutions that are optimal for the company or the supply chain. The loyalty to different memberships has a similar challenge. Employees can 
IJLM 31,3

see themselves mainly as members of the company or of the supply chain, which may lead to belonging paradoxes between the company's prioritisation of requirements on packaging solutions, and the supply chain's prioritisation of the same (Vergese et al., 2010; White et al., 2015).

System level 2 considers employees' competing values, roles and memberships between the company and a subunit. The values, roles and memberships of packaging employees affect whether they mainly belong to the company or to a packaging subunit (e.g. the packaging development team). For instance, a development manager may have a great deal of freedom to carry out successful projects, even if his or her management style contradicts the guiding principles for corporate values (Leonard-Barton, 1992). Individuals' concern about belonging may also lead to paradoxical tensions with regard to prioritising between the company's requirements on packaging solutions and the subunit's prioritisation for the same (García-Arca and Prado Prado, 2008; Lockamy III, 1995). Employees who mainly belong to a subunit are likely to focus on aligning packaging solutions with the subunit's overall value, but they may overlook the company values if they differ, and vice versa. An example is that packaging developers may have responsibilities within, and focus on, material, functional and production features of packaging, whereas the company has sustainability and marketing priorities (de Koeijer et al., 2017a). The employees can also see themselves mainly as members of the company or of a subunit, which may lead to belonging paradoxes with regard to prioritising between the company's requirements on packaging solutions and the subunit's prioritisation of the same (García-Arca and Prado Prado, 2008).

\subsection{Learning paradoxes}

Learning paradoxes refer to tensions between old and new knowledge within organisations. These paradoxes occur when past understandings and beliefs face new experiences that bring new knowledge and understandings (Smith and Lewis, 2011). Learning paradoxes are a result of whether an organisation should build upon current knowledge or abandon it and bring in new knowledge as a means of creating the future. Learning paradoxes may occur between and within organisational levels, and among individuals.

On system level 1, the companies in a supply chain may have a different focus on packaging knowledge development leading to learning paradoxes. Some companies may focus on building on current capabilities and packaging knowledge for incremental packaging improvements, whereas others may want to fundamentally change the packaging knowledge base to create novel and innovative packaging solutions (Olander Roese, 2014). García-Arca et al. (2019) suggest developing an ecosystem of packaging knowledge by turning the supply chain into a learning organisation. Bramklev (2009), on the other hand, states that a request for packaging development is usually handed to one single organisation the packaging manufacturer, who is expected to have packaging knowledge. Such an approach may limit the capability to capture and incorporate unique information from customers and to transform the knowledge base to match major changes in stakeholder requirements (Olander Roese, 2014).

On system level 2, a company and its subunits may want to build on current capabilities and knowledge to improve packaging solutions incrementally. However, changed characteristics of the business environment may also require fundamentally new packaging knowledge to create novel and innovative packaging solutions (Olander Roese, 2014). These two approaches are often incompatible, leading to learning paradoxes for packaging development (Olander Roese, 2014). An example is the organisational capabilities of maintaining the current knowledge base of packaging in that organisation, while at the same time challenging this knowledge by acknowledging and absorbing emergent packaging knowledge (Olsson, 2006). 
If the focus is on adopting new, emergent knowledge, there are paradoxical tensions related to destroying current knowledge, and the risk of developing knowledge bases in subunits of the company that move in different directions, jeopardising the core knowledge supply chains base in the company (Olsson, 2006).

\section{Discussion}

This paper applies paradox theory to packaging logistics in order to develop a generic, conceptual framework for organisational paradoxes related to packaging systems used in supply chains. As packaging logistics is an integral part of SCM, the framework contributes to the operational understanding of SCM. This section describes the value of the framework on three levels of abstraction.

The first level of abstraction corresponds to the highest level of theoretical implications of this research. Paradox theory advances the knowledge and understanding of organisational tensions in packaging logistics compared to existing frameworks and models for this kind of analysis. One advantage of applying Smith and Lewis' (2011) categories of paradoxes is that the PPP framework covers not only paradoxical tensions related to packaging features and their impact on performance (the focus in previous frameworks), but it also covers three other categories of paradoxical tensions. The PPP framework thus has a wider scope than previous frameworks, with a clearer categorisation of paradoxes. It also ranges from paradoxes on two system levels: within a company; and in the supply chain. A second advantage is that paradox theory helps us to distinguish between tensions that are possible to settle, and the remaining paradoxes, which should be acknowledged to be managed over time. The distinction between tensions that can be settled and those that lead to paradoxes broadens the understanding and discussion of conflicts of interest in packaging logistics. Instead of viewing all differences in packaging requirements as trade-offs, this paper offers a more nuanced view by helping to distinguish between paradoxes and solvable tensions. This is valuable in order to understand how to tackle different packaging-related challenges. From a practical perspective, acknowledging and understanding paradoxes can reduce intra- and inter-organisational frustration about fixed paradoxical tensions. It can also provide direction about where companies should invest and innovate in order to change the prerequisites for packaging paradoxes in the long term.

The second level of abstraction concerns the application of the PPP framework. It offers a structure for analysing the supply chain impacts of packaging. The framework supports the need to consider packaging from a strategic perspective (Freichel et al., 2020), which Lockamy III (1995) outlined as important more than twenty years ago, but still needs more support (Pålsson, 2018). Whereas Lockamy III proposed a framework with a cross-functional approach within a company, this research acknowledges the fact that packaging affects several organisations in the supply chain and thus extends the strategic perspective on packaging to include internal and external paradoxes for all stakeholders. The application of the PPP framework helps researchers and practitioners to understand the impacts of strategic packaging decisions on the supply chain. It helps to identify and categorise contextspecific paradoxes and other tensions for stakeholders in the supply chain in four categories. As a result, the framework improves the ability for researchers to map, position and further develop a general understanding of different types of tensions, such as paradoxes, related to packaging logistics. The application of the framework for a particular packaging solution can highlight different stakeholders' paradoxical tensions before the packaging solution is implemented. The application can also support packaging development by distinguishing between paradoxes for alternative packaging solutions.

The third level of abstraction refers to ways to tackle or manage packaging paradoxes. After acknowledging packaging paradoxes, the organisations involved need to find ways to 
IJLM 31,3

manage these paradoxes to avoid deadlocks, also referred to as paradoxical sensemaking (Xiao et al., 2018). The PPP conceptual framework supports this level of abstraction in that it helps to identify and structure packaging paradoxes. In-depth analysis of, and guidance on, managing packaging paradoxes, however, are outside the scope of this paper. Here, the overall view of packaging paradoxes is highlighted. It should be emphasised that managing a paradox is not the same as settling it or making a trade-off. Instead, it is about using the paradox as a driver for innovation, long-term transformation, and to increase the general understanding and explanations of current dynamics within organisations. Future research can be inspired by Smith and Lewis (2011) who suggest that managing paradoxes "fosters learning and creativity" (p. 393) and "helps individuals, groups, and firms to be flexible and resilient, fostering more dynamic decision making" (p. 394). They also highlight the need to be aware of the risk of organisations returning to past practices. Further support is provided in Jarzabkowski et al. (2013) in their proposed process model of how managers can respond to paradoxes.

The PPP conceptual framework is generic. It can be applied to identify categories of paradoxes for various types of packaging systems in various types of supply chains. When the framework is applied, contextual factors determine which of the generic paradoxes need the most emphasis. One example involves contextual factors related to market segments. For instance, fruit produced in South America may be packed and supplied in one type of packaging system domestically, and in another in the global supply chains ending in Europe. Furthermore, consumers in some countries prefer apples, bananas and other fruit and vegetables in sales packaging, whereas consumers in other countries prefer buying by weight. Another example involves the contextual factors related to sales channels such as conventional trade with stores and e-commerce with home delivery. For instance, the performing paradoxes that stem from primary packaging sold both in stores and via ecommerce are often related to promotional features (more important in the store) compared to packaging features related to logistics efficiency and protection (often more important in ecommerce). A third example is that contextual factors related to products, such as shelf life, price, temperature sensitivity, and product maturity affect the extent to which different packaging paradoxes are emphasised. Logistically efficient packaging may need to be developed for mature products, whereas new and innovative products may need packaging that is visually attractive and displays innovation. This can give rise to organising paradoxes about aligned packaging solutions for different products. These and other considerations of contextual factors should be addressed in future research.

\subsection{Implication for practitioners}

The theoretical implications discussed so far are also relevant for practitioners. The paper elaborates on the PPP conceptual framework to further emphasise its content and guide logistics-, supply chain- and packaging managers. Acknowledging packaging paradoxes in packaging logistics research has implications for practitioners that can help to identify organisational development opportunities for improved packaging-related practices through a "dualities aware perspective" (Graetz and Smith, 2009). The application of paradox theory helps managers to distinguish between unsolvable paradoxes and tensions that can be settled. The PPP conceptual framework and its capability to identify, categorise and describe inherent paradoxical tensions related to packaging can be combined with utilisation and exploitation of the paradoxes into a first step in redesigning intra- and inter-organisational packaging-related practices.

As outlined earlier, the PPP conceptual framework offers several advantages for research; these can be transformed into practical implications. For logistics-, supply chain- and packaging managers, the conceptual PPP framework: 
(1) Categorises paradoxical tensions related to packaging to acknowledge and evaluate their meaning for, and impact on, organisations, supply chains and packaging performance.

(2) Extends the traditional view of managing trade-offs related to packaging features to cover organisational paradoxes and tensions in four categories.

(3) Supports the needs for packaging innovation initiatives.

These points show that overall, the PPP conceptual framework can support strategic packaging decisions because it can help organisations understand and evaluate the impact of packaging decisions on different organisational levels.

\section{Conclusions and future research}

Research and practice have, to some extent, started to follow Lockamy III's (1995) suggestion to view packaging as a key strategic resource to ensure competitive advantage in the marketplace. This paper provides further guidance on this path.

By applying paradox theory to packaging logistics, this paper develops a new framework that conceptually deepens knowledge about, and understanding of, requirements and expectations on packaging from several stakeholders. The paper builds on the notion that "enormous opportunities exist to integrate insights from organization theory and supply chain management in order to build understanding of why some supply chains excel while others do not" (Ketchen and Hult, 2007, p. 455) and that paradox theory promotes a holistic view and pushes researchers to consider the nature of paradoxical tensions and how to manage them (van der Byl and Slawinski, 2015). Compared to previous knowledge, the PPP framework offers better opportunities to describe, explain and interconnect paradoxical tensions related to packaging on two organisational levels: between organisational subunits in a company, and between supply chain organisations.

It is well established in the research on packaging in logistics and supply chain management that there are many requirements and expectations on packaging, some of which are inconsistent. The current literature recommends that trade-offs be addressed by a combination of packaging features that result in the greatest total value from a system perspective. The PPP conceptual framework contributes to knowledge enhancement through increased understanding of packaging paradoxes and their organisational impacts. The framework's systematic categorisation in four areas, with thorough descriptions of the meaning of packaging paradoxes in each area, offers an expanded and in-depth explanation of the organisational impacts of packaging. The distinction between paradoxes and tensions is discussed; it provides a valuable contribution to packaging logistics and logistics management research. These considerations of contradictory goals and objectives have fallen under the more generic term "trade-offs" in previous research. The distinction made here, through the lens of paradox theory, increases the understanding in packaging logistics of these contradictions in terms of the different characteristics of paradoxes and other tensions that can be settled. To tackle paradoxes and settle other tensions, the framework emphasises that innovative solutions should be sought.

The current work has limitations that offer at least five essential future research themes. First, although the proposed PPP framework constitutes an important platform for identification and understanding of paradoxical tensions, it should be noted that the conceptual framework does not include any specific information or guidance on how to manage such paradoxes. For instance, it does not provide any advice on how to prioritise different paradoxes. Neither does it offer any guidance on how to exploit paradoxes for innovation and development purposes. Future research should target strategies and approaches for the utilisation of paradoxes as a managerial tool. Smith and Lewis (2011), as 

IJLM
31,3

well as Schad et al. (2016) and Gaim and Wåhlin (2016), have presented initial research on this matter, but additional conceptual and empirically driven research within the packaging logistics domain should study underlying processes and procedures that are required to prioritise and exploit paradoxes for innovation and development purposes.

Second, as an extension of the above research theme, the issue of how to judge management practices of packaging paradoxes remains open for more research. This includes in what dimensions and on what scales such management activities should be judged. It also includes how managerial efforts can be measured in relation to our proposed framework, particularly at different hierarchical levels. The existing, nascent research on various management strategies (e.g. Smith and Lewis, 2011; Gaim and Wåhlin, 2016) may constitute a basis on which future research on these matters can be built. This research should include multiple, independent actors who simultaneously manage packaging paradoxes, preferably with a supply chain perspective.

Third, the actual content in the proposed PPP framework with its four categories is also a potential theme for future research efforts. The proposed framework applies a theorybuilding approach with description and explanation, as outlined by Meredith (1993). The next step is to test and refine the content in the framework as a means of evaluating and confirming it (Meredith, 1993). In doing so, both qualitative and quantitative data from different packaging contexts are valuable. The refinement should include improved specifications of sub-categories within each paradox category. The testing should embrace Smith and Lewis's idea (2011) that paradoxes may occur between the four paradox categories; testing should thus examine interdependencies between paradoxes both within and between intra- and interorganisational levels. In particular, empirical research should test links between the four paradox categories on both system levels to illustrate how the four categories are related to each other.

Fourth, a theme for future research is to study the impact of contextual factors on the proposed PPP framework. Empirical research should play an important role for knowledge development about how various contextual factors, such as size and length of the supply chain, and the degree and characteristics of collaborative relationships, may impact on the four categories of packaging paradoxes. Such research would also offer more practical illustrations of packaging paradoxes.

Finally, a theme to examine is to further study the impact on packaging logistics research of changing perspective from making trade-offs between various packaging requirements to paradoxical thinking. In this paper, we have discussed such impacts on different levels of abstraction. Future research may extend this discussion of a changed perspective by scrutinising and relating dilemmas, trade-offs, dialectics, dualities and paradoxes in packaging logistics.

\section{References}

Azzi, A., Battini, D., Persona, A. and Sgarbossa, F. (2012), "Packaging design: general framework and research agenda", Packaging and Technology and Science, Vol. 25, pp. 435-456.

Bortolini, M., Galizia, F.G., Mora, C., Botti, L. and Rosano, M. (2018), "Bi-objective design of fresh food supply chain networks with reusable and disposable packaging containers", Journal of Cleaner Production, Vol. 184, pp. 375-388.

Bramklev, C. (2009), “On a proposal for a generic package development process”, Packaging Technology and Science, Vol. 22, pp. 171-186.

Brix-Asala, C., Geibusch, A.-K., Sauer, P.C., Schöpflin, P. and Zehendner, A. (2018), "Sustainability tensions in supply chains: a case study of paradoxes and their management", Sustainability, Vol. 10 No. 2, pp. 1-20. 
Çankaya, S.Y. and Sezen, B. (2019), "Effects of green supply chain management practices on sustainability performance", Journal of Manufacturing Technology Management, Vol. 30 No. 1, pp. 98-121.

Christopher, M. (2016), Logistics and Supply Chain Management, 5th ed., Financial Times Professional, London.

Corley, K. and Gioia, D. (2011), "Building theory about theory building: what constitutes a theoretical contribution?”, Academy of Management Review, Vol. 36 No. 1, pp. 12-32.

Damanpour, F. (1991), "Organizational innovation: a meta-analysis of effects of determinants and moderators", Academy of Management Journal, Vol. 34 No. 3, pp. 555-590.

de Koeijer, B., de Lange, J. and Wever, R. (2017a), "Desired, perceived, and achieved sustainability: trade-offs in strategic and operational packaging development", Sustainability (Switzerland), Vol. 9 No. 10, pp. 1-29.

de Koijer, B., Wever, R. and Henseler, J. (2017b), "Realizing product-packaging combinations in circular systems: shaping the research agenda", Packaging Technology and Science, Vol. 30, pp. 443-460.

Defee, C.C., Williams, B., Randall, W.S. and Thomas, R. (2010), "An inventory of theory in logistics and SCM research", The International Journal of Logistics Management, Vol. 21 No. 3, pp. 404-489.

Franey, J.P., Okrasinski, T.A. and Schaeffer, W.J. Jr (2010), "Reducing environmental impact and increasing reliability through packaging: a lifecycle assessment approach”, Bell Labs Technical Journal, Vol. 15 No. 2, pp. 193-204.

Freichel, S.L.K., Wollenburg, J. and Wörtge, J.K. (2020), "The role of packaging in omni-channel fashion retail supply chains: how can packaging contribute to logistics efficiency?", Logistics Research, Vol. 13 No. 1, pp. 1-20.

Gaim, M. and Wåhlin, N. (2016), "In search of a creative space: a conceptual framework of synthesizing paradoxical tensions", Scandinavian Journal of Management, Vol. 32, pp. 33-44.

García-Arca, J., González-Portela Garrido, A.T. and Prado-Prado, J.C. (2017), “'Sustainable packaging logistics": the link between sustainability and competitiveness in supply chains", Sustainability (Switzerland), Vol. 9 No. 7, pp. 1-17.

García-Arca, J., Trinidad González-Portela, A. and Carlos Prado-Prado, J. (2019), “Organizational best practices in packaging design. An analysis in perfumery and cleaning products", Direccion $y$ Organizacion, Vol. 68, pp. 5-19.

García-Arca, J. and Prado Prado, J.C. (2008), "Packaging design model from a supply chain approach", Supply Chain Management: An International Journal, Vol. 13 No. 5, pp. 375-380.

Gebert, D., Boerner, S. and Kearney, E. (2010), "Fostering team innovation: why is it important to combine opposing action strategies?”, Organization Science, Vol. 21 No. 3, pp. 593-608.

Graetz, F. and Smith, A.C.T. (2009), "Duality theory and organizing forms in change management", Journal of Change Management, Vol. 9 No. 1, pp. 9-25.

Grönman, K., Soukka, R., Järvi-Kääriäinen, T., Katajajuuri, J.-M., Kuisma, M., Koivupuro, H.-K., Ollila, M., Pitkänen, M., Miettinen, O., Silvenius, F., Thun, R., Wessman, H. and Linnanen, L. (2013), "Framework for sustainable food packaging design", Packaging and Technology and Science, Vol. 26, pp. 187-200.

Hahn, T., Pinkse, J., Preuss, L. and Figge, F. (2015), "Tensions in corporate sustainability: towards an integrative framework", Journal of Business Ethics, Vol. 127, pp. 297-316.

Hahn, T., Figge, F., Pinkse, J. and Preuss, L. (2018), "A paradox perspective on corporate sustainability: descriptive, instrumental, and normative aspects", Journal of Business Ethics, Vol. 148 No. 2, pp. 235-248. 
IJLM
31,3

Halldórsson, A., Hsuan, J. and Kotzab, H. (2015), "Complementary theories to supply chain management revisited - from borrowing theories to theorizing", Supply Chain Management: An International Journal, Vol. 20 No. 6, pp. 574-586.

Hargrave, T.J. and van de Ven, H. (2017), "Integrating dialectical and paradox perspectives on managing contradictions in organizations", Organization Studies, Vol. 38, pp. 319-339.

Hellström, D. and Olsson, A. (2017), Managing Packaging Design for Sustainable Development, Wiley, West Sussex.

Hellström, D. and Saghir, M. (2007), "Packaging and logistics interactions in retail supply chains", Packaging Technology and Science, Vol. 20, pp. 197-216.

Jarzabkowski, P., Lê, K.J. and van de Ven, A.H. (2013), "Responding to competing strategic demands: how organizing, belonging, and performing paradoxes coevolve”, Strategic Organization, Vol. 11 No. 3, pp. 245-280.

Kassaye, W. and Verma, D. (1992), "Balancing traditional packaging functions with new "green" packaging concerns”, SAM Advanced Management Journal, Vol. 135 No. 4, pp. 15-23.

Ketchen, D.J. and Hult, G.T.M. (2007), "Toward greater integration of insights from organization theory and supply chain management", Journal of Operations Management, Vol. 25 No. 2, pp. $455-458$.

Klevås, J. (2005), "Organization of packaging resources at a product-developing company”, International Journal of Physical Distribution and Logistics Management, Vol. 35 No. 2, pp. 116-131.

Klevås, J., Johnsson, M. and Jönson, G. (2006), “A packaging redesign project at IKEA”, in Arlbjørn, J.S., Halldórsson, Á., Jahre, M., Spens, K. and Stefansson, G. (Eds), Nordic Case Reader in Logistics and Supply Chain Management, Syddansk Universitetsforlag.

Kovacs, G. and Spens, K. (2007), "Logistics theory building", ICFAI Journal of Supply Chain Management, Vol. 4 No. 4, pp. 7-27.

Lai, J., Harjati, A., McGinnis, L., Zhou, C. and Guldberg, T. (2008), "An economic and environmental framework for analyzing globally sourced auto parts packaging system”, Journal of Cleaner Production, Vol. 16 No. 15, pp. 1632-1646.

Leonard-Barton, D. (1992), "Core capabilities and core rigidities: a paradox in managing new product development", Strategic Management Journal, Vol. 13, pp. 111-125.

Lewis, M.W. (2000), "Exploring paradox: toward a more exploring comprehensive guide", Academy of Management Review, Vol. 25 No. 4, pp. 760-776.

Lewis, M. and Smith, W. (2014), "Paradox as a metatheoretical perspective: sharpening the focus and widening the scope", The Journal of Applied Behavioral Science, Vol. 50 No. 2, pp. 127-149.

Livingstone, S. and Sparks, L. (1994), "The new German packaging laws: effects on firms exporting to Germany", International Journal of Physical Distribution and Logistics Management, Vol. 24 No. 7 , pp. 15-25.

Lockamy, A. III (1995), "A conceptual framework for assessing strategic packaging decisions”, The International Journal of Logistics Management, Vol. 6 No. 1, pp. 51-60.

Luscher, L. and Lewis, M. (2008), "Organizational change and managerial sensemaking: working through paradox", Academy of Management Journal, Vol. 51, pp. 221-240.

Maalouf, M. and Gammelgaard, B. (2016), "Managing paradoxical tensions during the implementation of lean capabilities for improvement", International Journal of Operations and Production Management, Vol. 36 No. 6, pp. 687-709.

MacInnis, D.J. (2011), “A framework for conceptual contributions in marketing”, Journal of Marketing, Vol. 75 No. 4, pp. 136-154.

Mahmoudi, M. and Parviziomran, I. (2020), "Reusable packaging in supply chains: a review of environmental and economic impacts, logistics system designs, and operations management", International Journal of Production Economics, Vol. 228, pp. 1-15. 
March, J.G. (1991), "Exploration and exploitation in organizational learning”, Organization Science, Vol. 2 No. 1, pp. 71-87.

Matthews, L., Power, D., Touboulic, A. and Marques, L. (2016), "Building bridges: toward alternative theory of sustainable supply chain management", Journal of Supply Chain Management, Vol. 52, pp. 82-94.

Meredith, J. (1993), "Theory building through conceptual methods", International Journal of Operations and Production Management, Vol. 13, pp. 3-11.

Molina-Besch, K. and Pålsson, H. (2014), "Packaging for eco-efficient supply chains: why logistics should get involved in the packaging development process", in Macharis, C., Melo, S., Woxenius, J. and Lier, T. Van (Eds), Sustainable Logistics, Emerald Group Publishing (Transport and Sustainability), pp. 137-163.

Molina-Besch, K. and Pålsson, H. (2016), "A supply chain perspective on green packaging development: theory versus practice", Packaging Technology and Science, Vol. 29, pp. 45-63.

Mollenkopf, D., Closs, D., Twede, D., Lee, S. and Burgess, G. (2005), "Assessing the viability of reusable packaging: a relative cost approach", Journal of Business Logistics, Vol. 26 No. 1, pp. 169-197.

Nosella, A., Cantarello, S. and Filippini, R. (2012), "The intellectual structure of organizational ambidexterity: a bibliographic investigation into the state of the art", Strategic Organisation, Vol. 10 No. 4, pp. 450-465.

Olander Roese, M. (2014), "From powerpoints to reality: managing strategic change in the paper packaging industry", Doctoral thesis, Lund University, Lund, Sweden.

Olsmats, C. and Dominic, C. (2003), "Packaging Scorecard: a packaging performance evaluation method", Packaging Technology and Science, Vol. 16, pp. 9-14.

Olsson, A. (2006), "The change from feature focus to customer focus in packaging development", Doctoral thesis, Lund University, Lund, Sweden.

Pålsson (2018), Packaging Logistics: Understanding and Managing the Economic and Environmental Impacts of Packaging in Supply Chains, Kogan Page, London.

Pålsson, H. and Hellström, D. (2016), "Packaging logistics in supply chain practice - current state, trade-offs and improvement potential", International Journal of Logistics Research and Applications, Vol. 19 No. 5, pp. 351-368.

Pålsson, H., Finnsgård, C. and Wänström, C. (2013), "Selection of packaging systems in supply chains from a sustainability perspective: the case of Volvo", Packaging Technology and Science, Vol. 26 No. 5, pp. 289-310.

Paine, F.A. (1990), Packaging Design and Performance, Pira, Leatherhead/Surrey.

Poole, M.S. and van de Ven, A. (1989), "Using paradox to build management and organizational theory", Academy of Management Review, Vol. 14, pp. 562-578.

Sandberg, E. (2017), "Introducing the paradox theory in logistics and SCM research: examples from a global sourcing context", International Journal of Logistics Research and Applications, Vol. 20 No. 5, pp. 459-474.

Santén, V. (2017), "Towards more efficient logistics: increasing load factor in a shipper's road transport", International Journal of Logistics Management, Vol. 28 No. 2, pp. 228-250.

Schad, J., Lewis, M.W., Raisch, S. and Smith, W.K. (2016), "Paradox research in management science: looking back to move forward", Academy of Management, Vol. 10 No. 1, pp. 5-64.

Selviaridis, K., Matopoulos, A., Szamosi, L.T. and Psychogios, A. (2016), "Reverse resource exchanges in service supply chains : the case of returnable transport packaging", Supply Chain Management: An International Journal, Vol. 21 No. 3, pp. 381-397.

Slawinski, N. and Bansal, P. (2012), "A matter of time: the temporal perspectives of organizational responses to climate change", Organization Studies, Vol. 33 No. 11, pp. 1537-1563. 
IJLM
31,3

Slawinski, N. and Bansal, P. (2015), "Short on time: intertemporal tensions in business sustainability", Organization Science, Vol. 26 No. 2, pp. 531-549.

Smith, W.K. and Lewis, M.W. (2011), "Toward a theory of paradox: a dynamic equilibrium model of organizing", Academy of Management Review, Vol. 36 No. 2, pp. 381-403.

Steenis, N.D., van Herpen, E., van der Lans, I.A., Ligthart, T.N. and van Trijp, H.C.M. (2017),"Consumer response to packaging design: the role of packaging materials and graphics in sustainability perceptions and product evaluations", Journal of Cleaner Production, Vol. 162, pp. 286-298.

Svanes, E., Vold, M., Möller, H., Pettersen, M.K., Larsen, H. and Hanssen, O.-J. (2010), "Sustainable packaging design: a holistic methodology for packaging design", Packaging Technology and Science, Vol. 23 No. 3, pp. 161-175.

Trent, R.J. and Monczka, R.M. (2003), "Understanding integrated global sourcing", International Journal of Physical Distribution and Logistics Management, Vol. 33 No. 7, pp. 607-629.

Twede, D. and Clarke, R. (2005), "Supply chain issues in reusable packaging", Journal of Marketing Channels, Vol. 12 No. 1, pp. 7-26.

van der Byl, A. and Slawinski, N. (2015), "Embracing tensions in corporate sustainability: a review of research from win-wins and trade-offs to paradoxes and beyond", Organization and Environment, Vol. 28, pp. 54-79.

Vangen, S. (2012), "Understanding, investigating and theorizing inter-organizational collaborations: a focus on paradox", in BAM 2012: Management Research Revisted: Prospects for Theory and Practice, pp. 1-11.

Verghese, K. and Lewis, H. (2007), "Environmental innovation in industrial packaging: a supply chain approach", International Journal of Production Research, Vol. 45 Nos 18-19, pp. 4381-4401.

Verghese, K.L., Horne, R. and Carre, A. (2010), "PIQET: the design and development of an online streamlined LCA tool for sustainable packaging design decision support", International Journal of Life Cycle Assessment, Vol. 15 No. 6, pp. 608-620.

Wacker, J. (1998), “A definition of theory: research guidelines for different theory-building research methods in operations management", Journal of Operations Management, Vol. 16 No. 4, pp. 361-385.

Waldman, D.A., Putnam, L.L., Miron-Spektor, E. and Siegel, D. (2019), "The role of paradox theory in decision making and management research", Organizational Behavior and Human Decision Processes, Vol. 155, pp. 1-6.

Wannags, L.L. and Gold, S. (2020), "Assessing tensions in corporate sustainability transition: from a review of the literature towards an actor-oriented management approach", Journal of Cleaner Production, Vol. 264, pp. 1-15.

White, G.R.T., Wang, X. and Li, D. (2015), "Inter-organisational green packaging design: a case study of influencing factors and constraints in the automotive supply chain", International Journal of Production Research, Vol. 53 No. 21, pp. 6561-6566.

Xiao, C., Wilhelm, M., van der Vaart, T. and van Donk, D.P. (2019), "Inside the buying firm: exploring responses to paradoxical tensions in sustainable supply chain management", Journal of Supply Chain Management, Vol. 55 No. 1, pp. 3-20.

\section{Corresponding author}

Henrik Pålsson can be contacted at: henrik.palsson@plog.lth.se

For instructions on how to order reprints of this article, please visit our website:

www.emeraldgrouppublishing.com/licensing/reprints.htm

Or contact us for further details: permissions@emeraldinsight.com 